\title{
Improving the performance of small and medium Iranian businesses through strategic alignment and market response
}

\author{
Hanif Zarafshan ${ }^{1}$, Mahsa Keshavarzpour ${ }^{2}$, Hadi Alizadeh ${ }^{3}$ \\ 1.Department of Management, Islamic Azad University, Shiraz Branch, Shiraz, Iran. \\ 2.Islamic Azad university, Tehran (Fars) Science and Research Branch. \\ 3.Department of Management, Islamic Azad University, lamerd Branch, lamerd, Iran.
}

\begin{abstract}
Strategic alignment refers to the integration and coordination of applications of information technology and organizational goals. In this area, not only information technology programs should reflect goals, missions and business strategies, but business programs should also be referred to as an information technology program, applications and specific technologies It be. This research was conducted to evaluate the performance of small and medium Iranian businesses through strategic alignment and market response. In this research, the research variables were evaluated by a questionnaire. The questionnaire was distributed between 383 samples from the statistical population, which is all managers and experts of small and medium Iranian businesses. The research method was descriptive correlational. To answer the questions and examine the research hypotheses with SMART-PLS software, structural equation and path analysis was used by minor least squares method (PLS). The results of this study indicate that strategic alignment, factory technology capability, customization ability, delivery capabilities and cost control over company performance are positive and significant.
\end{abstract}

Key words: Strategic alignment, market accountability, company performance, small and medium Iranian businesses

\section{1- Introduction}

Organizations need information systems and technologies that can help them increase success, offer new products and better services (Issa-Salwe et al., 2010). There are many approaches about how to react to the changing world. All of these approaches are only meaningful if they involve alignment in the organization as a infrastructure and very important principle. Increasing competition in the market today has continuously forced senior executives to evaluate each of its key applications and share its company competition and business performance (Sardana et al., 2016). This need to specify the best strategy, in each part of the organization (Laugen et al., 2005) and its integration across the organization's sectors (Calantone et al., 2002). The consistency is the degree and extent that the needs, demands, goals, purpose or structure of a component, are consistent with the needs, demands, goals, purpose, or other component structure. The alignment is a moving target that is thrown and abandoned in organizations, and alignments between two or more organizational dimensions, which can interact interaction, are essential for the development of performance (Sardana et al., 2016).

The idea and the need for "strategic consensus" or "alignment" of competitive priorities among different sectors in an organization that was initially concepted by Skinner (1974). Since then, strategic alignment of production and marketing operations as "best practice" has been widely proposed and is highly needed that leads to a competitive advantage to participate in the market (Ang et al., 2015).

Similarly, other studies show that as long as the company does not have a proper strategy and responding to the market needs, only using advanced manufacturing technology can not be improved by business performance (Amoako et al, 2008). Also, studies have shown production requirements for alignment with other sectors, especially marketing (Marques et al., 2014; Paiva, 2010; Karmarkar, 1996; Shapiro, 1977). 
However, based on the gap in the literature of the strategy strategy, it should be claimed that the issue of layout of operations with strategy and marketing has not been widely examined in an agency, and when studied, researchers rarely influence it Have been examined on company performance. In this research, the benefits obtained from the strategic alignment of the overall examination of operational functions that arise from its integration with marketing and reviewing the market in small and medium Iranian businesses. In this research, also examines the effect of these two important and dynamic aspects on the company's performance (company technology capability and company competition capabilities that include cost management and delivery capability), this approach is a comprehensive understanding of the importance of each These key factors and its impact on the performance of the company. Therefore, the present study tries to fix this research vacuum. In particular, the purpose of this study is to answer the question of how strategic alignment and market accountability affect the performance of the company?

\section{2- Theoretical foundations}

\section{2-1- Strategic alignment}

In the definition and description of alignment, according to the structures and the vocabulary used to describe and model it, there is a very significant variety (Hill \& Brown, 2007, Venkatraman \& Camillus, 1984). This is one of the main problems about reviewing and analyzing related research, using the key of existing vocabulary and also providing a structured structure as a knowledge tree. In this study, from these two words "homewel" and "alignment" are used in a sense.

Perhaperious phrases such as strategic fit, strategic alignment (sometimes used in meaning), as well as strategic coherence, are used to associate meaning such as proportionality, coherence, compatibility and consistency between different organizational dimensions. (Prieto \& Carvalho, 2011).

Although the widespread and occasion of existing contradictions, the researcher will try to examine alignment in definitions, structures, and forms of existing existing, while describing each of each, a general pattern as a knowledge tree.

According to studies, alignment can have a multitude, structural and conceptual variation:

- Diversity depends on definitions and meanings;

- Diversity depends on the position of alignment in strategic management;

- Diversity depends on the forms of creating and flogging of homework;

- Diversity is dependent on the structure of variables and concepts that are homework in their study.

Henderson and Vanctarman define strategic matching strategic fit and integrity of the work strategy between business strategy, information technology strategy, infrastructure and organizational processes, infrastructure and information systems processes. Plameter and Marcus consider the use of information technology in a consistent manner in the company's overall strategies (Sardana et al., 2016).

\section{2-2- Competitiveness}

So far, many definitions have been made from different perspectives regarding competitiveness. Competitiveness is a process that includes people, resources, decisions and quality. In the last two decades, we have witnessed two different schools in competitiveness. Technology-based approaches and competence approach. Based on the first approach, technology is the basis of competitiveness, while the basis of the second approach is the learning organization, which emphasizes the changes in the strengths through algamation, as well as predictive and responsive effectiveness.

Scott defines competitiveness as the ability to increase revenues at a speed of competitors and the creation of essential capital to confront them in the future (Scott, 2007). Buckley believes that competitiveness includes performance (achieving goals with minimal cost) and ability (having the right goals) and the choice of appropriate goals is of great importance. The competitiveness of both goals and access to goals is included (Buckely, 2004).

De Cruz and Ragman, believe that the company's competitiveness can be defined as a power of design, production, or presentation of products against competitors, lower price or higher quality versus cost (D'cruz \& Rugman, 2007). Competitiveness from the American Competitiveness Association: Competitiveness means the ability to increase production through the creation of high-level goods and 
services that can provide a good response to global market criteria (Chang et al., 2014).

In the competitiveness report of the Canadian intelligence industry, it is noted that corporate competitiveness that can maintain or increase market share while creating an acceptable return of capital. Therefore, competitiveness is identified by market share and profitability. By examining all the above definitions, each of them expresses one of the dimensions affecting the competitiveness of countries in a particular industry. Also, given the changes that occurred in an international economic environment, none of these theories were not sufficient to express the cause of countries trade and the reason for the success of a country in particular industrial and the ability of a country in maintaining their competitive position in the long run and need Providing a theory that can be found beyond the reasons for the competitiveness of an industry globally (Garelli, 2005).

\section{2-3- Functional performance}

The company's performance is based on how to perform missions, tasks and organizational activities and the results of their performances. In another definition, the performance of the company is to achieve organizational and social goals or beyond them and carry out the responsibilities of the organization. According to Nani et al (1990), performance measurement is the process of ensuring that a organization is pursuing strategies that lead to the realization of goals. Moolin (2002) emphasizes the performance measurement, on how to manage and value the management of organizations and their value for customers and other benefits (Amaratunga \& Baldry, 2002).

Measurement of performance as a process of determining the amount of efficacy and efficiency of past actions (Cho et al., 2014) and as one of the most necessary controls of the control task - one of four elements of knowledge and management knowledge - in organizations, and Measuring the status quo used as a basis for decision making on continuing, modifying or preventing the work that is taking place. The performance assessment systems of organizations are an important mechanism of control in the direction of the policy and general policies of the organization and provide important and vital information about the proportion and adaptation of the performance of units with programs. Of course, this depends on the fact that the performance evaluation system has adequate comprehensiveness so that its results can be used and all aspects of activities (Amaratunga \& Baldry, 2002).

In the past, the success of organizations is only evaluated on the basis of financial measures, but with increasing market competition, in addition to financial measures, other aspects of the organization's performance were also considered, hence, due to the importance of measuring performance for organizations. He describe the performance of an organization should be addressed for non-financial dimensions. For this purpose, various frameworks and models have been proposed for measuring performance, with European qualitative prize models and Baldaich and framework prize, such as the pyramid, and a balanced scorecard of this sentence (Evers, 2010).

In general, the financial criteria of performance measurement are preferable because of its quantitative and objective features, in principle, the financial criteria that have been raised in relation to performance evaluation can be two categories of accounting models. Classified economic. In accounting models, company performance is evaluated according to accounting data. Some of the most important of these criteria include profits, per share, free cash flows, asset returns and return on equity. In economic models, the company's performance is evaluated according to the power of acquisition of existing assets and its potential investments, and with the rate of return and capital costs. The most important criteria in the field of performance evaluation using economic criteria are worth added market and economic value added (Chang et al., 2014).

However, it should be considered that the performance measurement is practice of measurement of performance (Radnor \& McGuire, 2004). Performance measurements play an important role and an important tool in implementing competitive strategies that can lead to improved company performance.

In measuring performance, there are two major approaches: objective and two approaches have their own advantages and disadvantages: objective scales are more real, but are limited in terms of coverage of financial data and other organizational dimensions are not explained. On the other hand, mental scales are less realistic, but they provide a rich description of the organization's effectiveness. This scale allows a wide range of organizations compared to various industries. Therefore, the generalizations of the findings are based on more mental scales. Also, the mental scales of perception-based analysis elements 
also cover a special place in social science research. The question, which of these approaches should be considered in measuring performance, depends on organizational orientation and type of attitude of managers (Allen et al., 2008).

Generally not accepted method for measuring corporate performance, but usually financial results and financial results, the ultimate goal of many companies, experimental studies show that the performance of a multidimensional structure should be measured with several criteria.

\section{2-4- Conceptual Research Model}

Given that the purpose of this research is to investigate the performance of small and medium Iranian business performance through strategic alignment and market accountability, so the general framework of this research is also systematic and principled in order to explain the above subject. To assess the assumptions of this research, the concept model is used in Figure 1. All research studies are based on a conceptual framework, which identifies the desired variables and relationships between them. This conceptual framework is a pattern that the researcher is based on the relationships between factors that are recognized in the creation of an important problem. Does the theory. This theory can not necessarily be the word of research and logically derive from the results of the previous investigation.

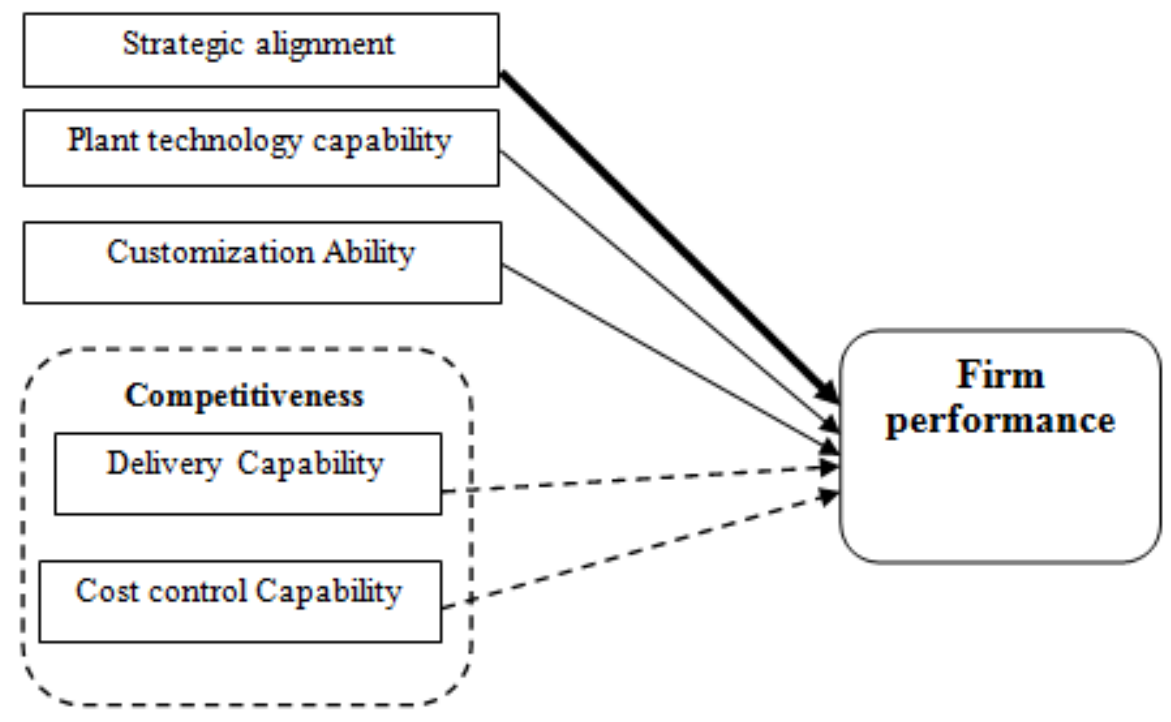

Figure 1: Conceptual model of research

\section{3- Research methodology}

In terms of methodology, this research is correlational research. The present study is one of the descriptive research based on how to obtain the required data and in terms of research classification according to their purpose. This research is applied in terms of descriptive-survey method.

In this research, in order to formulate the basics, definitions and theoretical concepts of library resources, boutes, books and scientific articles used were also used to collect data needed to test the assumptions of the research. Information about the measurement of research data was collected with a valid questionnaire. In this questionnaire, the strategic alignment of 7 questions, the factory technology capability questionnaire 5 questions, the ability to customize 4 questions, delivery capability 2 questions, cost control, and company performance. The questionnaire was designed and developed by Sardana et al. (2016).

The statistical population of this study includes small and medium Iranian businesses. Based on the definition of the World Trade Organization: small and medium enterprises are defined as companies that employ 10 to 250 people. Enterprises with up to 10 employees are usually called wisdom companies and companies with more than 250 corporate employees. Also, according to the software research, which has used the Small and Industrial Township of Iran for studying small and medium businesses, we also 
sought to use this database and found that the main source of information in relation to business The small and medium work of the Ministry of Industry, Mining and Trade. After correspondence and contact with the ministry, we received information about Iran's businesses that included 192872 businesses. Of these 125,365 businesses, according to the above and moderate definition.

In this study, simple random sampling method was used to select the samples and the research questionnaire was randomly distributed among managers and experts of small and medium Iranian businesses. Among the sampling methods with equal probabilities, simple random sampling method is one of the easiest and oldest sampling methods in practice. If an instance of $n$ from a population of $n$ is selected in such a way that each sample of $\mathrm{N}$ may have the same chance of being selected, it is called simple random sampling. Simple random sampling can be applied in two sampling methods with placement and sampling without placement, but it does not apply to sampling with plastering.

Considering that the volume of the statistical population is limited to 125,365 people, the Cochran formula is used to select the sample size. The Cochran formula is one of the most widely used methods to calculate the statistical sample size. Therefore, the sample size in this study is 383 people.

\section{4- Data analysis}

In this research, structural equation modeling has been used with the help of partial least squares method and PLS software to test the hypotheses and accuracy of the model. PLS is a variance-based approach that requires fewer conditions than similar techniques to structural equations such as LISREL and AMOS. Its main advantage is that this type of modeling requires fewer samples than LISREL. It is also considered as a powerful method in situations where the number of samples and measurement items is limited and the distribution of variables can be uncertain. PLS modeling is done in two steps. In the first stage, the measurement model should be examined through validity and reliability analyzes and confirmatory factor analysis, and in the second stage, the structural model should be examined by estimating the path between variables and determining the model fit indices.

\section{4-1- Step 1: Measurement model}

The measurement model test is related to checking the validity and reliability of measuring instruments.

\section{4-1-1- Validity}

To evaluate the convergent validity, AVE (average variance extracted) and CR (composite reliability) were used. The results of this criterion for the dimensions of the six research variables are shown in Table (1). Composite reliability higher than 0.7 and mean variance higher than 0.5 are two necessary conditions for convergent validity and correlation of structures. As can be seen from Table (2), all composite reliability values are higher than 0.7 and the values of mean variance are higher than 0.5 , and this confirms that the convergent validity of the present questionnaire is acceptable.

Table 1: Results of mean variance extracted from research structures

\begin{tabular}{|c|c|c|c|c|c|c|}
\hline Variable & $\begin{array}{c}\text { Strategic } \\
\text { alignment }\end{array}$ & $\begin{array}{c}\text { Plant } \\
\text { technology } \\
\text { capability }\end{array}$ & $\begin{array}{c}\text { Customization } \\
\text { Ability }\end{array}$ & $\begin{array}{c}\text { Delivery } \\
\text { Capability }\end{array}$ & $\begin{array}{c}\text { Cost } \\
\text { control } \\
\text { Capability }\end{array}$ & $\begin{array}{c}\text { Firm } \\
\text { performance }\end{array}$ \\
\hline AVE & $0 / 561$ & $0 / 735$ & $0 / 582$ & $0 / 623$ & $0 / 624$ & $0 / 575$ \\
\hline CR & $0 / 888$ & $0 / 809$ & $0 / 909$ & $0 / 846$ & $0 / 845$ & $0 / 921$ \\
\hline
\end{tabular}

In the divergent validity part, the difference between the indices of one structure and the indices of other structures in the model is compared. This is calculated by comparing the AVE root of each structure with the values of the correlation coefficients between the structures. To do this, a matrix must be formed in which the principal diameter values are the square matrix of the AVE coefficients of each structure and the lower values of the principal diameter are the correlation coefficients between each structure and other structures. This matrix is shown in Table (2). As can be seen from Table (2), the AVE root of each structure is greater than the correlation coefficients of that structure with other structures, which indicates 
that the divergent validity of the structures is acceptable.

Table 2: Comparison matrix of AVE root with correlation coefficients of structures (divergent validity)

\begin{tabular}{|c|c|c|c|c|c|c|}
\hline & $\begin{array}{l}\text { Strategic } \\
\text { alignment }\end{array}$ & $\begin{array}{c}\text { Plant } \\
\text { technology } \\
\text { capability }\end{array}$ & $\begin{array}{c}\text { Customization } \\
\text { Ability }\end{array}$ & $\begin{array}{l}\text { Delivery } \\
\text { Capability }\end{array}$ & $\begin{array}{c}\text { Cost } \\
\text { control } \\
\text { Capability }\end{array}$ & $\begin{array}{c}\text { Firm } \\
\text { performance }\end{array}$ \\
\hline Strategic alignment & $0 / 749$ & & & & & \\
\hline $\begin{array}{c}\text { Plant technology } \\
\text { capability }\end{array}$ & $0 / 661$ & $0 / 857$ & & & & \\
\hline $\begin{array}{l}\text { Customization } \\
\text { Ability }\end{array}$ & $0 / 651$ & $0 / 740$ & $0 / 763$ & & & \\
\hline Delivery Capability & $0 / 257$ & $0 / 324$ & $0 / 432$ & 0/795 & & \\
\hline $\begin{array}{c}\text { Cost control } \\
\text { Capability }\end{array}$ & $0 / 458$ & $0 / 341$ & $0 / 458$ & $0 / 458$ & $0 / 790$ & \\
\hline Firm performance & $0 / 664$ & $0 / 376$ & $0 / 442$ & $0 / 321$ & $0 / 552$ & $0 / 758$ \\
\hline
\end{tabular}

\section{4-1-2- Reliability}

In addition to Cronbach's alpha coefficient, which is presented in Table 3 and confirms the appropriate reliability of the questionnaire, the PLS method was used to evaluate the reliability of the questionnaire. The PLS method uses index reliability. The reliability of the index is also measured by measuring the factor loads by calculating the correlation value of the indices of a structure with that structure, which if this value is equal to or greater than 0.6, confirms that the reliability in The case for that is an acceptable measurement model. However, if the value of the factor load between a question and the relevant dimension is less than 0.6, that question can be removed from the model and subsequent analyzes. As can be seen in Figure $(2,3)$, all values of factor loads between structures and questions are greater than 0.6, which shows a high correlation.

Table 3: Cronbach's alpha coefficient

\begin{tabular}{|c|c|c|c|c|c|c|}
\hline $\begin{array}{c}\text { Research } \\
\text { structures }\end{array}$ & $\begin{array}{c}\text { Strategic } \\
\text { alignment }\end{array}$ & $\begin{array}{c}\text { Plant } \\
\text { technology } \\
\text { capability }\end{array}$ & $\begin{array}{c}\text { Customi } \\
\text { zation } \\
\text { Ability }\end{array}$ & $\begin{array}{c}\text { Delivery } \\
\text { Capability }\end{array}$ & $\begin{array}{c}\text { Cost control } \\
\text { Capability }\end{array}$ & Firm \\
performance \\
\hline $\begin{array}{c}\text { Cronbach's } \\
\text { alpha }\end{array}$ & $0 / 860$ & $0 / 705$ & $0 / 879$ & $0 / 836$ & $0 / 712$ & $0 / 825$ \\
\hline
\end{tabular}




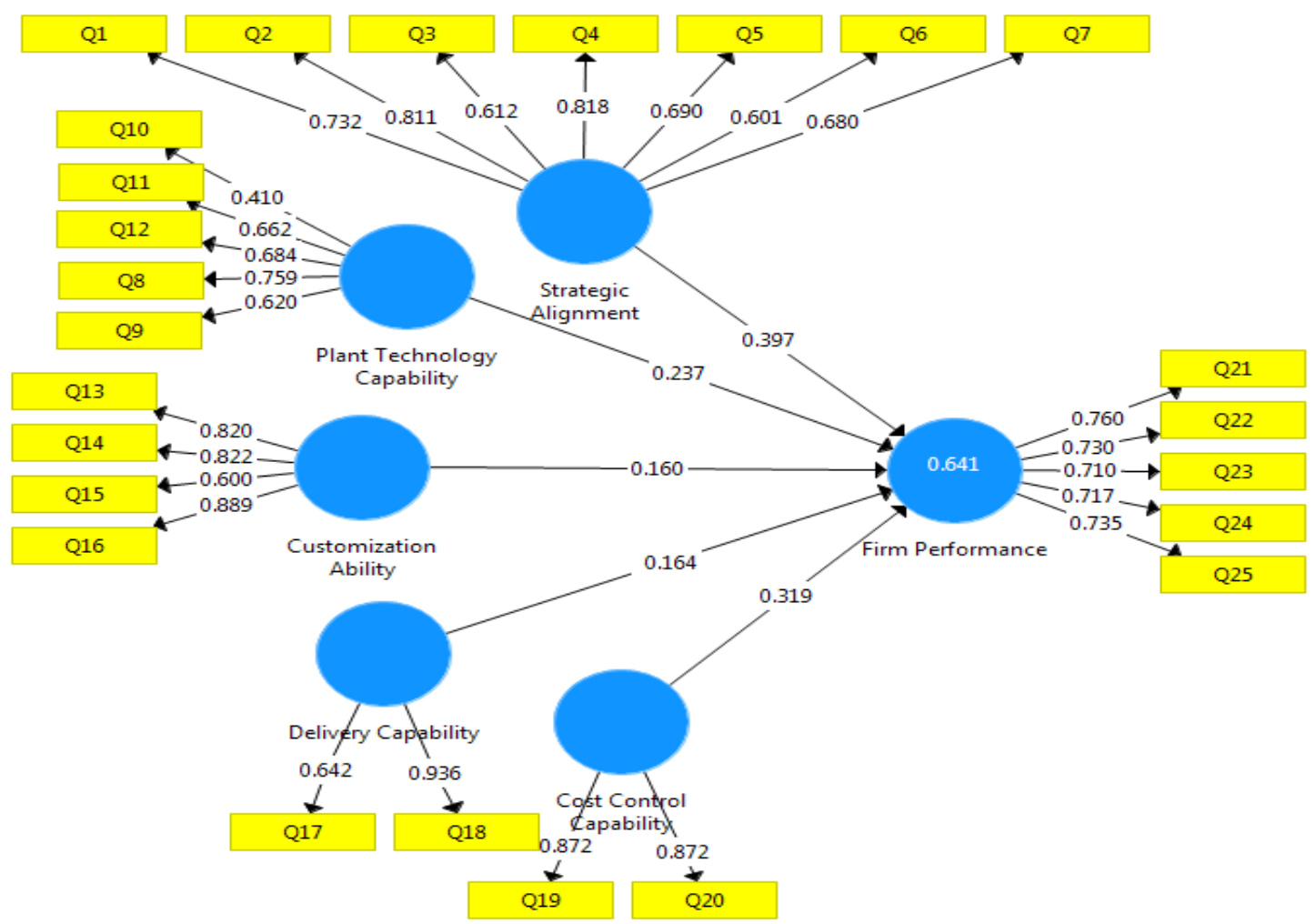

Figure 2: Software output - test model of the research (path coefficients and operating loads) 


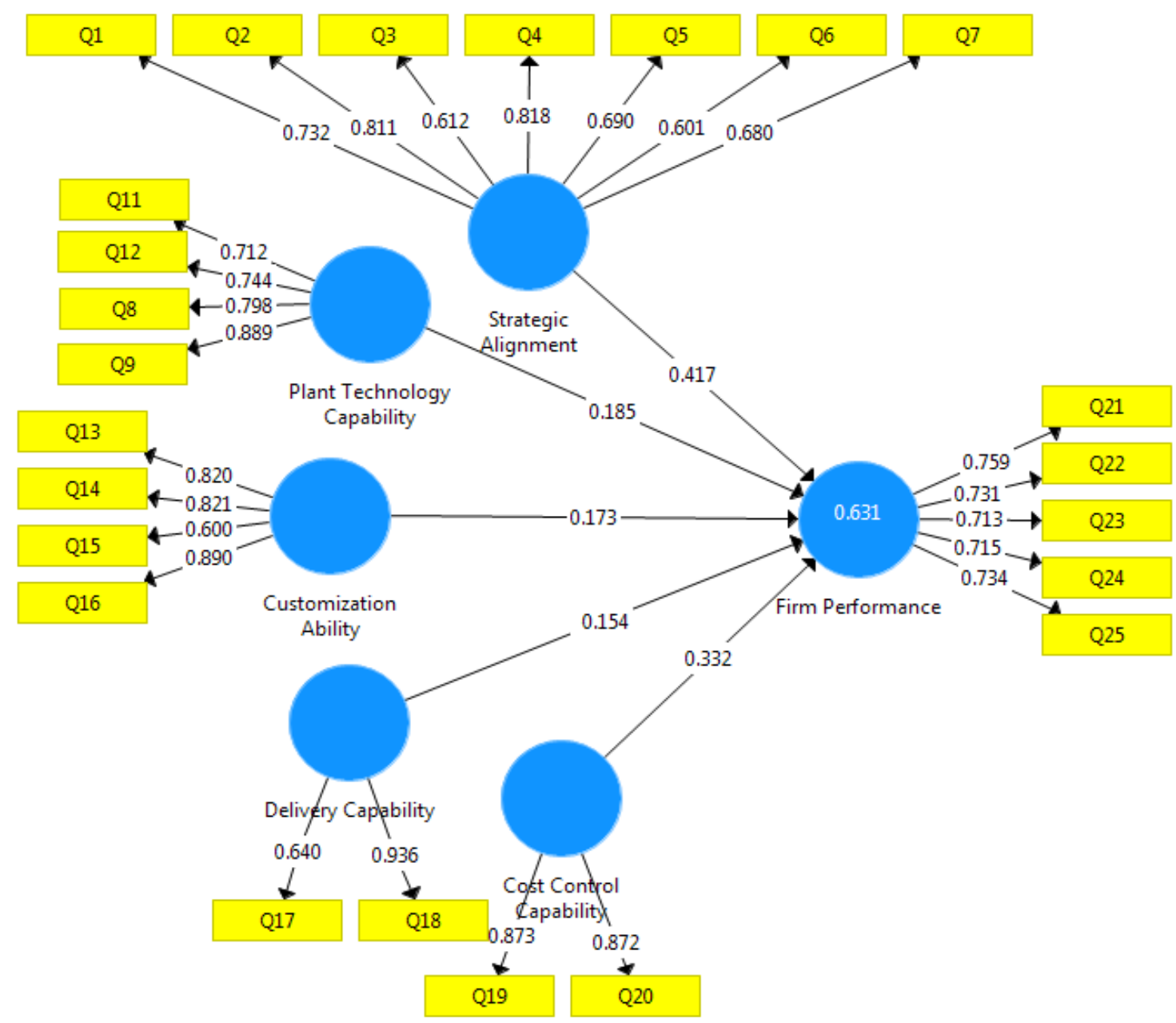

Figure 3: Software Output - Modified Research Model (path coefficients and operative loads).

\section{4-2- Second stage: structural model and testing of hypotheses}

Structural model test, which is related to testing research hypotheses and the effect of hidden variables on each other. To confirm the research hypotheses, the Bootstrapping command of Smart PLS software was used, which shows the output of t-coefficients (Figure 4). When the values of $t$ in the range are more than +1.96 and less than -1.96 , it indicates the significance of the relevant parameter and subsequently confirms the research hypotheses. 


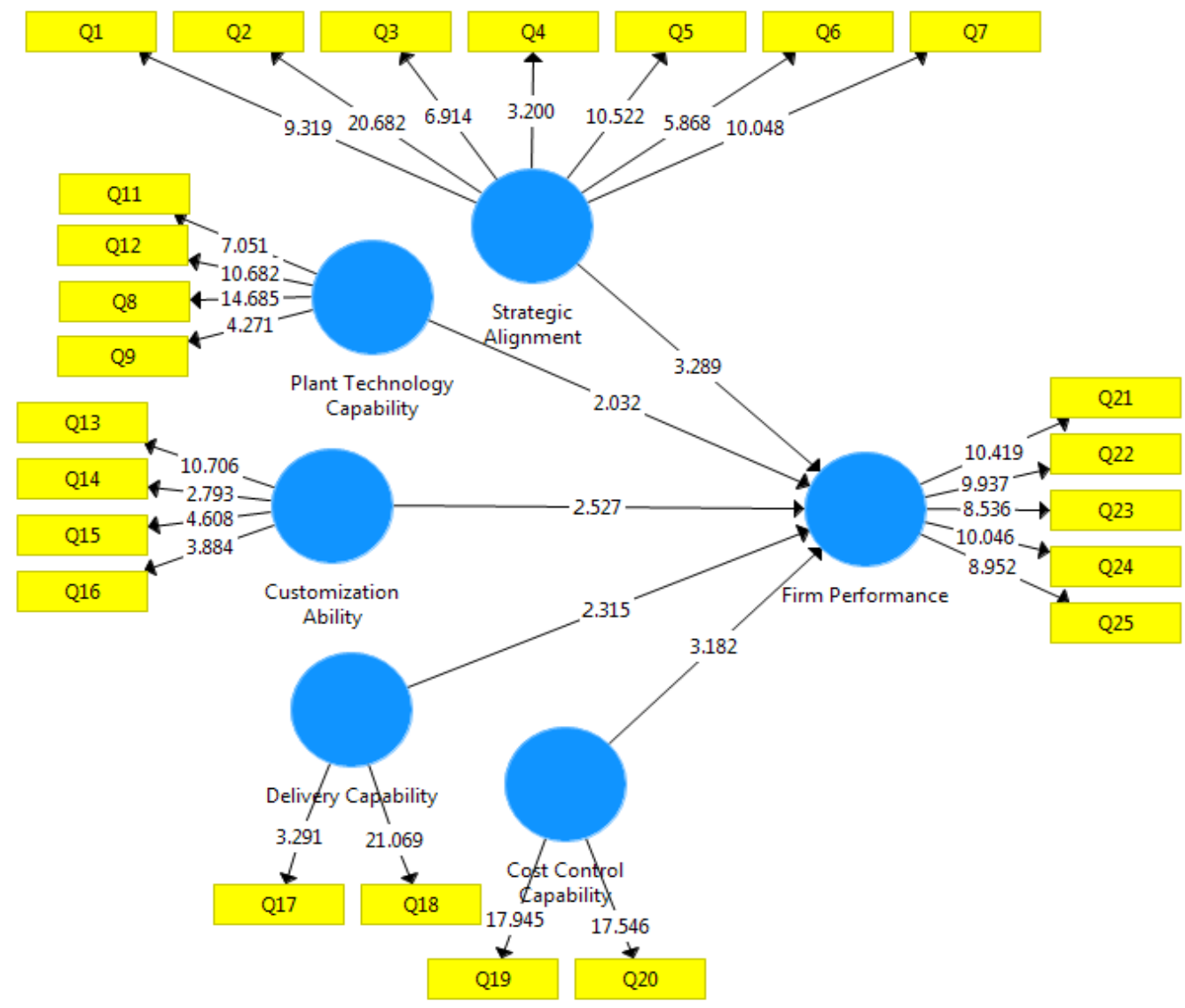

Figure 4: Software output - coefficients t

\section{4-3- Methods of evaluating shaping models}

One of the ways to evaluate the formor models is the coefficient of determination (R2). The coefficient of determination (R2) examines several percent of the variance of a dependent variable is explained and explained by the independent variable (s). Therefore, it is natural that this amount for an independent variable is equal to zero and for the dependent variable is higher than zero. The more frequently, the coefficient of the effect of independent variables on the dependent is higher. According to the coefficient of designation, the strategic alignment variables, factory technology capability, customization capability, delivery and cost control capabilities have been able to explain 0/631 of the variance of the company's performance variable; The researchers have introduced three values of $0.19,0.33$ and 0.67 as a criterion for weak, moderate and strong R2 values. Accordingly, it can be concluded that the model has a high prediction capability. The remaining amount of prediction error is related to other factors affecting the company's performance. 


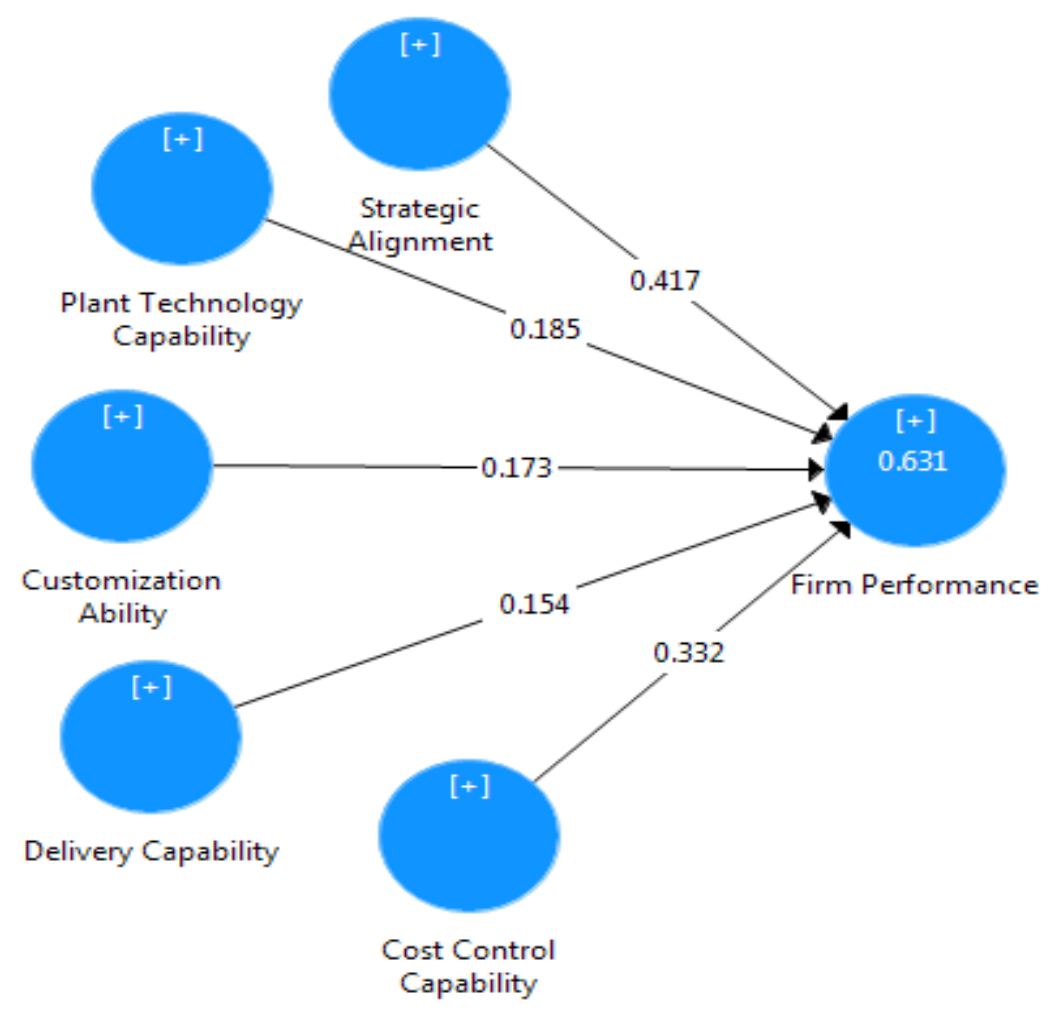

Figure 5: Evaluation of Shaping Models

\section{4-4- Answer to research hypotheses}

According to the results obtained from the path coefficient and $\mathrm{T}$, all assumptions of the research were confirmed, and the results showed that strategic alignment, plant technology capability, customization ability, delivery capability and cost control over participating company have a positive and significant impact have.

Table 4: Direct effects, t-statistic and the result of research hypotheses

\begin{tabular}{|c|c|c|c|c|}
\hline hypothesis & $\begin{array}{c}\text { Standardized path } \\
\text { coefficient } \beta\end{array}$ & statistics T & Meaningful & $\begin{array}{c}\text { No rejection or } \\
\text { Reject }\end{array}$ \\
\hline Strategic alignment $\rightarrow$ Firm performance & 0.417 & 3.289 & Sig<0.05 & approved \\
\hline Plant technology capability $\rightarrow$ Firm performance & 0.185 & 2.032 & Sig<0.05 & approved \\
\hline Customization Ability $\rightarrow$ Firm performance & 0.173 & 2.527 & Sig $>0.05$ & rejection \\
\hline Delivery Capability $\rightarrow$ Firm performance & 0.154 & 2.315 & Sig<0.05 & approved \\
\hline Cost control Capability $\rightarrow$ Firm performance & 0.332 & 3.182 & Sig<0.05 & approved \\
\hline
\end{tabular}

\section{5- Conclusions and suggestions}


Today, competition between companies has been very high. Companies have been influenced by multiple factors, such as globalization, technology development and increasing speed of new technologies. In the framework of this new perspective, companies must act differently for their survival and progress. In particular, it should be looking for new resources to be competitive advantage and use new forms of competition that requires a clear understanding of the nature and dynamics of the competition. In this regard, the most common features of the world today include globalization of the economy, mass production and surplus capacity in most markets, competition on time, mass information and communication and knowledge efficiency. This reflects the integrity of global markets and the increasing complexity of markets and the dynamics of ambitions on companies and organizations. In such a space, these basic questions can be designed to be the secret and survival and success of organizations in today's competitive world? Looking at the relevant literature and examining the views of strategic management specialists, answers the questions in creating, maintaining and continuing the sustainable competitive advantage, in the sense that organizations for immune from peripheral waves and compatibility with competitive requirements, except the style and continuity of the sustainable competitive advantage. They do not have.

This research has proven results. As you can see, strategic alignment has a significant impact on company performance. Therefore, any attention to strategic alignment and its indicators can lead to improved performance in corporate performance, as linking and constructing the strategy of different parts of the company to achieve common goals and strategies to all sectors of the company and the staff eventually leads to hands. The company's predetermined goals and ultimately improve performance of the company. Therefore, the company is expected to achieve this as strategic coherence and attention to its indicators.

According to the results of research technology, the company has a significant impact on performance of the company. The viewpoint of the business process from the perspective of technology capabilities argues that the high value of business is due to the root links of technology capabilities with business processes. In general, technology capabilities affect business processes (such as product development, quality management, production, and supply chain management), which, in turn, affect the company's performance. Researchers believed that technology capabilities provide infrastructure for business performance and its dependent processes. Recent advances in information systems research have shown that business process management capabilities are an important mediation between technology capabilities and performance of the company. Therefore, with the attitude of the company's technology capabilities, it can be expected to improve the company's performance.

According to the results obtained on the positive impact of the ability to customize the company's performance, it should be stated that when the organization reaches the ability to attract and pay attention to its customers, the ability to order based on order and instead of producing and Then selling their demands, regardless of the needs and demands of our customers, paid their demands and, according to their demands, based on the rates given to the production, will eventually not be able to improve the performance of the company away from the mind.

According to the results of the research, since the delivery capability has a positive and significant impact on the company's performance, therefore, it is expected that it is expected to implement principles to increase the delivery rate of ordered products, so that the delay is not created in this process. It needs to implement timely production methods and improve supply chain management and strengthen the company's distribution channel.

As you can see, cost control over company performance has a significant effect. Therefore, any attention to the management of costs in the production process and project projects and cost 
control of the company's performance leads to improved company performance because the cost control advantage is that the ability to detect deviations from programs in order to adopt corrective action and minimization of risk Provides. Therefore, by improving the cost control management system, it can be expected to improve company performance.

Therefore, according to the analytical set of functional suggestions for small and medium Iranian businesses below:

- Investigating and revised continuous production strategy and strategy notifications clearly to all employees

- Along with the production strategy with other sectors and coherence of production strategy with company strategy

- Establishing a production strategy as leverage available capabilities and provide clear definition of goals of production strategy

- Attempts to help the company's dedicated equipment gain competitive advantage and increase the superior technology skills of labor

- Create superior knowledge technology in factory and equip new equipment

- Create unique capabilities of production process and add product variation without sacrificing quality

- Ability to produce high types of products and the ability to introduce new products

- Ability to run new or change existing processes and attempts to increase delivery speed

- Increasing the reliability of delivery and reducing unit cost and total cost of unit goods

\section{References}

Amaratunga, D. \& Baldry, D. (2002). Moving from Performance Measurement to Performance Management, Facilities, Vo.20.No.5/6.p.217.

Amoako-Gyampah, K., Acquaah, M. (2008). Manufacturing strategy, competitive strategy and firm performance: An empirical study in a developing economy environment. International Journal of Production Economics 111(2), 575-592.

Ang, J. S. K., Shimada, T., Quek, S-A, Lim, E., (2015).Manufacturing strategy and competitive performance - An ACE analysis. International Journal of Production Economics169, 240-252.

Buckley , P. J. \& Prescott, K. (2003). "Measures of international competitiveness : A critical survey". Journal of marketing, (4) , $175-200$.

Calantone, R., Dröge, C., Vickery, S., (2002). Investigating the manufacturing-marketing interface in new product development: does context affect the strength of relationships? Journal of Operations Management20, 273-287.

Chao, Ch.A. Chandra, A. (2016). Impact of owner's knowledge of information technology (IT) on strategic alignment and IT adoption in US small firms. Journal of Small Business and Enterprise Development, Vol. 19 Iss: 1 pp. $114-131$

Chang, H., Hsiao, H., Lee, Y., Chang, J. (2014). Assessing IT-business alignment in service-oriented enterprises. Pacific Asia Conference on Information Systems 2009, 1-11.

D'Cruz , j. \& Rugman , A. (2007). "New concepts for 12anadian competitiveness". Journal of marketing research , (1), $127-154$.

Evers, K. W. (2010). Business-IT alignment: a current-state evaluation of strategic alignment within the hospital organization. Dissertation for the degree doctor of philosophy, Capelle University.

Galeri , S. (2005). "Competitiveness of nations : The fundumenials , IMD word competitiveness year book ". 139 157.

Hill , C.W.\& Jonse , G,R. (2000). "Strategic management theory . $1^{\text {st }}$ Ed, Houghton miff line company , usa.

Hill, A., \& Brown, S. 2007, Strategic profiling: A visual representation of internal strategic fit in service organizations. International Journal of Operations \& Production Management, Vol.27 No.12, pp. 1333-1361.

Issa-Salwe, A., Ahmed, M., Aloufi, K. (2010). Strategic information systems alignment: alignment of IS/IT with business strategy. Journal of Information Processing Systems, 1(16), 121-128.

Karmarkar, U. S. (1996). Integrative research in marketing and operations management. Journal of Marketing Research 33 (2)125-133.

Laugen, B. T., Acur, N., Boer, H., Frick, J. (2005). Best manufacturing practices: What do the best-performing companies do? International Journal of Operations and Production Management 25 (2), 131-150. 
Marques, A., Lacerda, D. P., Camargo, L. F. R., Teixeira, R. (2014). Exploring the relationship between marketing and operations: Neural network analysis of marketing decision impacts on delivery performance. International Journal of Production Economics153,178-190.

Paiva, E. L., (2010). Manufacturing and marketing integration from a cumulative capabilities perspective. International Journal of Production Economics, 126, 379-386.

Prieto, V.C., \& Carvalho, M.M., 2011, Strategic alignment and performance: Brazilian companies in the medical diagnostics sector, The Service Industries Journal, Vol.31 No.9, pp.1405-1427.

Sardana, D. Terziovski, M. Gupta, N. (2016). The impact of strategic alignment and responsiveness to market on manufacturing firm's performance. Intern. Journal of Production Economics, http://dx.doi.org/10.1016/j.ijpe.2016.04.018

Scott , B. (2007). "competitiveness : self - help for a worsening problem". Harvard business review , (6), 115 - 121. Venkatraman, N., Camillus, J.C., 1984. Exploring the concept of 'fit' in strategic management, Academy of Management Review, Vol.9 No.3, pp. 513-525. 